\title{
Analysis of Staffing and Training Needs for Effective Delivery of Extension Service in Sustainable Land Management in Kilimanjaro Region, Tanzania
}

\author{
John F. Kessy \\ Department of Forest Economics, Sokoine University of Agriculture, Morogoro, Tanzania \\ Email: jfkessy2012@gmail.com
}

Received 7 October 2014; revised 5 November 2014; accepted 20 November 2014

Copyright (C) 2014 by author and Scientific Research Publishing Inc.

This work is licensed under the Creative Commons Attribution International License (CC BY). http://creativecommons.org/licenses/by/4.0/

cc) (7) Open Access

\section{Abstract}

An assessment of staffing and training needs for effective delivery of extension services in mainstreaming sustainable land management (SLM) practices in Kilimanjaro Region was conducted in June/July 2013. Data collection methods included discussions with key informants at the regional and district levels, consultations with village level stakeholders and potential collaborators, review of human resources data both at regional, district and ward levels and collection of individual staff bio-data including capacity deficiencies. The staffing situation at the regional and district levels was considered to be adequate for effective mainstreaming of SLM interventions in the region. Staffing at ward and village levels was very poor and largely inadequate for sustainable execution of extension services. It is optimistically estimated that on average the staffing at ward level needs to be increased by at least $50 \%$. In some districts the deficiency of extension staff at ward level was as high as $\mathbf{8 0 \%}$. Training needs exist at all levels from the region down to community level. At the regional and district levels both long and short term training programs were required. At the community level required training is more practical and purely focused in mainstreaming SLM interventions at individual households and community lands. Potential collaborators with local government were identified in four main categories namely, NGOs/CBOs, private sector, government departments and faith-based organizations. The study recommends a capacity building program on specific knowledge gaps identified at regional, district, ward and village levels. The study further recommends that immediate measures need to be taken by the district authorities to address the staffing problem at ward level including recruitment of volunteers and developing collaboration framework with identified potential partners.

\section{Keywords}

Staffing, Training, Extension Services, Sustainable Land Management 


\section{Introduction}

The Global Environment Facility (GEF) through UNDP has committed US \$2.63 million over a period of 4 years to contribute to reducing land degradation on the highlands of Kilimanjaro through implementation of actions targeting removal of barriers for Sustainable Land Management (SLM) in a multi-level approach. The project goal is to ensure "Sustainable Land Management provides the basis for economic development, food security and sustainable livelihoods while restoring the ecological integrity of the Kilimanjaro Region's ecosystems".

The Kilimanjaro ecosystem is experiencing an extensive process of degradation and deforestation, with serious consequences on its ability to continue providing ecosystem services and declining land productivity [1]-[3]. Degradation is driven by a set of complex and interrelated factors, such as rapid increase of a population largely dependent on natural resources, land use change, poor land management practices, unsustainable harvesting of natural resources, declining commodity prices and climate change. As in other parts of the country, local communities in Kilimanjaro are faced with a number of shocks for which they must develop coping strategies. Among the documented shocks [4] for example include climate change causing crop failure, economic hardships, health related shocks causing diseases and deaths, land use conflicts as well as policy related challenges.

The project intends to address four key barriers to sustainable land management in the region which are: limited livelihood opportunities outside the natural resources, weak incentives for adoption of SLM, weaknesses in the policy, planning and institutional environment that influence SLM, and inadequate skills at all levels required for promoting and/or adopting SLM. The project has a set of outputs linked to activities and interventions aimed to address the identified challenges. However, for the project outputs to be realized the capacities of the implementing agents on the ground particularly the regional and district technical teams need to be enhanced through a systematic capacity building program. The reported study aimed to assess the staffing and training needs for effective delivery of SLM related extension services in the region. Specifically, the study aimed to:

- Assess existing capacity for extension service delivery at regional, district and community level;

- Assess the required capacity and gaps for effective extension delivery;

- Identify best partnership practices between local government staff, NGOs and the private sector in delivering of extension services;

- Recommend a capacity bridging program involving partnerships and synergies with existing collaborators in the districts.

\section{Methodology Deployed}

A range of data-collection methodologies was deployed during the assessment to facilitate effective participation of key stakeholders and triangulate the findings objectively [5] [6]. The methodologies deployed are briefly described in the following sub-sections.

\subsection{Discussions with Key Informants in the Region}

This approach was used to collect information from the project management team, regional and district officials, and selected professional and technical staff using a specified data-collection checklist. At the regional level the key informants, among others included the Regional Technical Team, responsible for implementing the project, and other relevant administrators. At the district level discussions involved the District Facilitating Teams, technical officers, and other extension agents in the district. The data collection process was structured to capture comparable information from both the region and districts for triangulation purposes.

\subsection{Village/Community Level Discussions}

From the design stage of the assessment it was strongly felt that community needs and perceptions in relation to capacity building should be given attention. In each district one representative village was selected. In the selected village a consultative meeting was organized consisting of representatives from the community. Representatives included 5 members from the village government, 5 from village environmental committees, 3 members representing influential farmers in the village and 2 representatives who were female household heads.

\subsection{Collection of Bio-Data of Employees and Deficiencies}

Current data on employees was collected from the regional, district and ward offices. A special form was de- 
signed to capture the entire list of existing extension staff in the region and districts, their capacities and deficiencies.

\subsection{Reviews of Relevant Documents}

Various documents provided by the project, local government authorities and other stakeholders were reviewed. From these documents secondary information on the capacity status in the target districts was obtained. Particularly, human resources management data was reviewed from the personnel department files and planning documents at regional and district levels.

\subsection{Data Analysis}

Data was analyzed with the purpose of establishing existing capacities and gaps [7] [8] in relation to the provision of extension services for mainstreaming SLM activities at regional, district and ward/village levels. For qualitative information collected through checklists, content analysis was deployed to extract valuable pieces of information that add value to the assessment. Quantitative data especially on staffing levels was analyzed using standard statistical procedures.

\section{Results and Discussions}

\subsection{Analysis of Staffing Needs}

In the context of this assessment, staffing was contextualized to entail the process of acquiring, deploying, and retaining human resources of sufficient quantity and quality to create positive impacts on effective implementation of project interventions in Kilimanjaro Region [9] [10]. For purposes of providing extension services at the district, ward and village level as well as coordination at regional level, staffing is perceived as a management function of the regional and district authorities within the Local Government system in Tanzania. In this context it involves manning the regional, district, ward and village level administrative structures with the needed technical and extension officers for effective service delivery to the target population. This is supposed to be achieved through proper and effective selection, appraisal and development of the personnel in their respective positions to fulfill the roles assigned to them by employers [11]. It is in this context that the assessment was done to establish the staffing deficiencies at all levels in order to propose mechanisms through which the SLM project in collaboration with the local government structure in Kilimanjaro could improve the situation for a more effective delivery of extension services.

\subsubsection{Staffing at Regional Level}

Two categories of staff are responsible for mainstreaming SLM activities at the regional level. They include staff of the Economic and Productive Section within the regional administration structure and project staff employed by UNDP. Assessment of staffing needs considered both categories of staff, who actually from the Regional Technical Team. According to the establishment of the Economic and Productive Section (Table 1) the section is supposed to have an administrative secretary, 4 agricultural officers, 1 irrigation engineer, 2 agroengineers, 2 cooperative officers, 2 trade officers, 2 livestock officers, 1 veterinary officer, 1 forest officer, 1 game officer and 1 beekeeping officer.

Assessment of actual strength in the section shows that the section has deficiency of nine technical staff. Examining the staffing deficiency in relation to the task of mainstreaming SLM in the region it was apparent that lack of an irrigation engineer, two agro-engineers, one veterinary officer, and a beekeeping officer can adversely affect the mainstreaming of SLM activities in the region. This is because SLM interventions in the region require knowledge and professional skills from all disciplines including engineering, veterinary science and beekeeping. Discussions with the Regional Technical Team confirmed the fact that the shortage, especially of engineers has a bearing on delivery of extension services related to rehabilitation of degraded lands, and improvement of irrigation systems.

It was observed that most of the vacant positions at the regional level were already budgeted for (Table 1). What remained to be done was to fill the positions through normal recruitment procedures. Discussion with the regional team during the assessment revealed further that team spirit and holistic approaches have been promoted in delivering extension services to the communities. The inter-disciplinary approach that has been 
Table 1. Analysis of staffing and capacity deficiencies at regional level.

\begin{tabular}{cccccc}
\hline S/No & Position & Establishment & Actual & Deficiencies & Comment \\
\hline 1 & Assistant administrative secretary & 1 & 1 & 0 & Staffing as per requirement \\
2 & Agriculture officer & 4 & 4 & 0 & Staffing as per requirement \\
3 & Irrigation engineer & 1 & 0 & 1 & Approved in budget 2012/2013 \\
4 & Agro-engineer & 2 & 0 & 2 & Approved in budget 2012/2013 \\
5 & Cooperative officer & 2 & 1 & 1 & Approved in budget 2012/2013 \\
6 & Trade officer & 2 & 1 & 1 & Budgeted for the year 2013/2014 \\
7 & Livestock officer & 2 & 2 & 0 & Staffing as per requirement \\
8 & Veterinary officer & 1 & 0 & 1 & Approved in budget 2012/2013 \\
9 & Fisheries officer & 1 & 0 & 1 & Approved in budget 2012/2013 \\
10 & Forestry officer & 1 & 1 & 0 & Staffing as per requirement \\
11 & Game officer & 1 & 0 & 1 & Budgeted for the year 2013/2014 \\
12 & Beekeeping officer & 1 & 0 & 1 & Budgeted for the year 2013/2014 \\
& Total & 19 & 10 & 9 & \\
\hline \multicolumn{7}{r}{} & Regional staff employed by UNDP & & \\
\hline 1 & Position & Establishment & Actual & Deficiency & \\
\hline 3 & Technical advisor & 1 & 1 & 0 & Comment \\
\hline
\end{tabular}

adopted has minimized the impact of staff deficiency. Regarding the project staff that were employed by UNDP the assessment revealed that all established project positions at the regional level have actually been staffed. There is no deficiency in terms of project staff because the recruitment process by UNDP closely matched the requirements of the project and qualifications of the employed staff.

\subsubsection{Staffing at District Level}

Extension services for mainstreaming SLM activities at the district level were facilitated by the District Facilitation Team (DFT) under the leadership of a district focal person. The composition of the DFT is normally determined by the District Executive Director (DED) who appoints members of a DFT. During the appointment, the DED ensures that all the needed technical competences for handling sustainable land management issues are included in the team. Most common technical officers who constitute the DFT are drawn from relevant disciplines including agriculture, forestry, beekeeping, livestock development, community development, planning, land management and engineering. Composition of a DFT depends on existing professionals in a respective district. In total, the DFT is made up of eight members. The role of DFT is to facilitate the process of mainstreaming SLM interventions through delivery of extension services to the communities.

The assessment of staffing levels in the districts examined whether the DFTs had adequate staff for effective delivery of extension services. Since the DFT membership was drawn from relevant departments for SLM, it was implied that if the DFT was in place, adequately staffed and operational, extension service delivery in the districts would be smooth. It was revealed that in most of the districts staffing for implementation of SLM activities was adequate. It was only in two districts namely Mwanga and Rombo where deficiencies of 1 and 2 technical staff were respectively encountered. In terms of qualifications of the technical staff within the districts there was much variation. Most of the encountered staff either had a degree, an advanced diploma or an ordinary diploma. For implementing and sustaining SLM interventions in the districts, these qualifications were adequate. However, some capacity building in some specific areas of intervention shall be necessary as presented in the Section 3.2 of this paper.

\subsubsection{Staffing at Ward and Village Levels}

Eventually implementation of planned SLM intervention takes place in the target villages with facilitation from 
extension officers based either at the ward of village levels. During the assessment, it was therefore considered an issue of prime importance to assess existing staffing situation in the wards in order to establish staffing deficiencies which can adversely affect mainstreaming and sustaining SLM interventions in the region.

The ward level was purposely selected as the focus of analysis as opposed to village level for a number of reasons. In all the districts assessed, extension services at the community level were provided by extension offices based in the wards but serving a number of villages. In some instances, an extension officer served more that one ward. In very few incidences, some villages have village level extension officers. However, such villages were too few to direct the focus of the assessment at village level. The implication here is that it is more realistic to consider staffing at ward rather than village level if one needs to make an impact in terms staffing. As such, it was assumed that provision of extension services at the community level would largely depend on existing extension offers at the ward level.

The assessment took an inventory of existing extension officers in all the wards where the project is operational. The inventory took into consideration staffing requirement for each ward in terms of various disciplines that are relevant to SLM interventions. The assessment further established the number of existing staff in various disciplines and established staffing gaps or deficiencies based on the optional requirement of the wards. Findings indicate that in all the districts serious staffing deficiencies exist at ward level. As shown in Table 2 below, in terms of percentages the highest recorded staff deficiency was 80.5\% from Mwanga District followed by Siha (77\%), Same (71.4\%) Moshi Municipality (70\%), Hai (67\%), Rombo (64\%) and Moshi Rural (55\%).

It should be noted that the relatively lower percentage of deficit in Moshi Rural was actually a reflection of the fact that in several cases one extension officer was serving more than one ward. It should also be noted that the degree of deficiency depended much on the number of wards within the district which are involved in SLM interventions. For example Mwanga has a total of 11 wards and mostly has extension offices in agriculture and livestock production with very few community development officers and without foresters, beekeeping officers or water services attendants at ward level. This makes the staffing deficiency relatively high. When all the target wards were considered together staffing deficiency at ward level was found to be about $54 \%$. It can, therefore, be implied that the wards where SLM interventions are implemented, have only about half of the required extension staff. Yet, this is an optimistic estimate. Depending on available resources, the local government authorities in collaboration with partners can target to reduce this deficiency by a percentage say (e.g., 50\%) and apportion the recruitments based on demand in various wards. The staffing, can either be in terms of employed project extension staff, volunteers supported by the project or combination of both categories.

\subsection{Analysis of Training Needs}

In the context of this assessment training was considered in contemporary terms as an integral part of a comprehensive and systematic program addressing capacity issues, on how to use available technology best suited to the project's goals and embedded in a personnel development plan [9] [10]. It was further perceived that training should constitute build-in incentives on the part of project implementation staff to apply the new skills and should empower trainees to train others in using the technology. This is expected to influence staff performance in delivering extension services. As such, training was not considered to be stand alone and one-off interventions but rather a continuous process of capacity building in the region [7] [8]. New skills and competences are

Table 2. Staffing and capacity deficiencies at ward level in all the districts.

\begin{tabular}{cccccc}
\hline \multirow{2}{*}{ District } & Number of ward & \multicolumn{4}{c}{ Ward staff deficiencies \% } \\
\cline { 3 - 6 } & & Required & Present & Deficiency (number) & Deficiency (\%) \\
\hline Mwanga & 11 & 77 & 15 & 62 & 80.5 \\
Same & 3 & 21 & 6 & 15 & 71.4 \\
Siha & 2 & 13 & 3 & 10 & 77 \\
Hai & 6 & 42 & 14 & 28 & 67 \\
Mosh Rural & 13 & 91 & 41.7 & 50.3 & 55 \\
Moshi Urban & 10 & 70 & 21 & 99 & 70 \\
Rombo & 2 & 14 & 106 & 176 & 54 \\
\hline
\end{tabular}


developed responding to specific individual and community needs. This conceptualization guided the assessment process. The assessment of training needs was done for all the levels of SLM implementation including regions, districts, and ward/village levels. In each level the assessment was guided by the roles and responsibilities of staff and other stakeholders at that level in provision of extension services for mainstreaming SLM interventions in the region.

\subsubsection{Regional Level}

The regional team is responsible for overall coordination of the SLM interventions for the whole region. It is more strategic in nature with leadership and management roles including overall project cycle management. The assessment revealed that two categories of training needs exist at the regional level. They include both long and short term training programs. Long term training is required for some staff who would like to increase their professional competences. They include regional staffs who are interested to increase their qualifications and attain either graduate or post-graduate trainings. Short term training needs are very much related to acquisition of knowledge and skills in order to increase the capacity of regional staff to comfortably handle the coordination role. These are needed for almost all staff at the regional level. It was expressed during the assessment process that short training covering one to two weeks should be organized to provide knowledge and skills on some thematic areas of interest to SLM. The most relevant thematic areas include:

- Leadership and management skills;

- Strategic planning skills;

- Result based monitoring and evaluation skills;

- Project cycle management skills;

- Team building and communication skills;

- Conflict management skills.

It is proposed that the trainings should be formal in nature facilitated by resource person from within the country mostly to be drawn from existing institutions of higher learning and competent NGOs/private sector.

\subsubsection{District Level}

At the district level the assessment revealed that this is where intensive training and capacity building is needed. This is because the district team is responsible not only for the coordination and supervision of implementation of SLM activities in the district but also because it is envisaged that trainings at ward and village level should be facilitated by the district teams. Additionally the responsibility of integrating SLM interventions in the district planning process and ensuring acceptability by political structures in the districts rests with the District Facilitating Teams (DFTs). It is therefore important to ensure that the district teams are competent in most of the SLM technologies and practices. The assessment revealed that similar to the regional team, the district teams need both long and short duration training programs. A number of needed thematic training areas of training were identified to be relevant to the district teams. These include the following:

- Agroforesty technology;

- Alternative energy technologies;

- Alternative livelihood options and income generation activities at local level;

- Beekeeping skills;

- Tree nursery techniques and technologies;

- Soil erosion control mechanisms;

- Socio-economic survey methods;

- Survey and mapping skills (including the use of GPS);

- Water-harvesting techniques;

- Non-timber forest products harvesting and value addition;

- Fish farming techniques;

- Computer applications and database management;

- Project cycle management including M \& E;

- Geographical information systems;

- Contemporary livestock production technologies;

- Team building and communication skills;

- Lobbying and advocacy skills; 
- Business administration and financing mechanism (options at local level);

- PES options including REDD+;

- Efficient irrigation technologies.

It is proposed that training at the district level be provided to all relevant technical staff using the Training of Trainers (ToT) approach, the implication being that the district teams have to train those at lower levels. The training should combine theoretical orientation, practical skills and resources allowing some study tours to concretize the practical skills. The proposed duration of the training at the district level is two weeks whereby the first week is spent on theoretical orientation while the second week is used for practical skills including a study tours. The training should be organized within the region but rotating among the districts. Selection of the district where a particular training can be hosted should be guided by the possibility of carrying out practical training in that particular district on the thematic training area. For example, soil-erosion control training should be conducted in a district where soil erosion is a serious problem. As for the study tours, they can be organized within the region or outside depending particular skills required.

\subsubsection{Ward and Village Levels}

As pointed out earlier it expected that training at ward and village levels should be facilitated by the district teams. In situations where specific practical skills are needed and an NGO or institution in the private sector or FBO partner has the needed skills, collaboration between the district team and the partners should be sought to optimize learning. This may apply for example in areas of alternative energy technologies, nursery techniques, beekeeping, and water harvesting and efficient irrigation systems where a number of partners working in the districts have knowledge and experience as summarized in Section 8 of this report.

The assessment reveled that relevant training at ward and village levels should be on practical skills and adoption of technology as opposed to theoretical concepts. The most relevant thematic areas were identified and they include:

- Alternative energy technologies;

- Livelihood options and micro-financing mechanisms;

- Tree nursery and agroforestry technologies;

- Soil erosion control mechanisms;

- Beekeeping skills;

- Non-timber forest product collection and value addition;

- Water harvesting and efficient irrigation technologies.

It is proposed that the training approach should focus on demonstrations, practical orientation and study tours for practical learning. The trainings should best be organized at ward level and should rotate from one ward to another within the district taking advantage of peculiarities of different wards in relation to required SLM interventions.

\subsection{Analysis of Community Perceptions on Existing Capacities}

During the assessment process, deliberate efforts were made to get community-level opinion in relation to existing capacities to implement and sustain SLM interventions. In each district, a representative village was selected and a consultative meeting arranged. The consultations aimed first to establish whether villagers are aware of the SLM introduced interventions and how community members participate. It was revealed that all the involved villagers were aware of a project. Villagers reported to participate in project activities including tree planting, soil-erosion control, forest protection, protection of water resources, beekeeping, improved agriculture practices, reviving of traditional irrigation systems, alternative energy sources, and engaging in income generation activities. Villagers were aware of what the project expected from the community which they summarized to be active participation in project activities including practicing improved land-management practices in their own farms.

When asked about their ability and capacity to actively and effectively participate in project activities, the trend in all the villages was to request for capacity building arguing that they did not have enough knowledge and resource for effective participation. Among the areas which they requested for training included:

- Improved agriculture and livestock keeping practices;

- Beekeeping;

- Soil erosion control and conservation;

- Establishment of tree nurseries and agroforestry; 
- Alternative energy sources;

- Income generation activities and micro-financing.

They also reported to need support in terms of improved crop variety seeds and livestock herds. When asked about their perceptions on the ability of extension officers to deliver good services, all the consulted villagers reported that extension officers are not enough. They requested for increased number of extension officers particularly in agriculture, livestock and forestry professionals. It was also pointed out by villagers that some extension officers need to be trained on recent development in agriculture.

Shortage of extension officers was reported to result into delays in terms of getting services as one extension officer was serving many villagers in the ward. Inquiries were made to find out whether villagers were willing, ready and capable of sustaining SLM interventions as introduced by extension officers in their localities. Findings indicated that in all the villages surveyed willingness existed. Most of the interviewed villagers were ready to adopt introduced SLM practices in their farms but expressed their need for capacity building and support in terms of:

- Marketing of farm produce;

- Trainings and employment of extension officers;

- Access to credit facilities;

- Access to seeds, seedlings and planting materials;

- Alternative incomes and sources of energy.

\subsection{Assessment of Potential Collaborators}

The possibility of collaborating with other actors in pursuing SLM interventions was examined. The other actors in this context included like-minded organizations such as NGOs, FBOs, the private sector and other government departments whose activities complement SLM interventions in the region. The assessment was done in every district and the findings are summarized in the following matrix (Table 3).

It should be noted that different modalities of engaging the potential collaborators exist. In some instances they can be sub contracted in others they can take part in project activities using their resources but also they can fundraise in collaboration with districts teams.

\section{Major Conclusions and Recommendations}

Through the assessment it has become possible to understand the existing situation in terms of staffing and training needs in the districts and wards where the SLM project is operational as well as at the regional secretariat where project coordination is affected. The major conclusions from the assessment include the following:

- The existing staffing situation at the regional and district levels is considered to be adequate for effective delivery of extension services. Where gaps exist for example at the regional level, mechanisms are already in place to fill the gaps including inclusion of the recruitment needs in annual budgets.

- Staffing at ward and village levels is very poor and largely inadequate for sustainable execution of project interventions. It is optimistically estimated that average the staffing at ward level needs to be improved by at least $50 \%$. In fact in some districts the shortage of extension staff at ward level is as high as $80 \%$. This is an area where the project can significantly make an impact in terms of staffing.

- Training needs exist at all levels from the region down to community level. At the regional and district levels both long term and short term trainings are required. While the former is for improving the professional skills of the staff the later is largely focused in ensuring that the needed knowledge and practical skills to handle planned project interventions are in place. At the community level required training is more practical and purely focused in mainstreaming SLM interventions at individual households and community lands.

- A number of potential collaborators were identified. They fall in four main categories namely, NGOs/CBOs, private sector, government departments and faith based organizations. Possible collaborating mechanisms included sub-contracting, joint ventures in fundraising, provision of training services and using partner's activities/interventions to complement SLM interventions in areas where the partner is working. However, deliberate efforts to initiate the envisaged collaboration should be taken by the project management team.

- A training program for the project covering all the levels has been proposed.

It is recommended that the SLM local government authorities in collaboration with the project management team should: 
Table 3. Identified potential partners, their activities and roles in SLM.

\begin{tabular}{|c|c|c|c|}
\hline District & Potential partner & Activities of the partner & Areas of collaboration \\
\hline \multirow{3}{*}{ Mwanga } & MIFIPRO & Irrigation, tree planting and beekeeping & Irrigation \& tree planting \\
\hline & TIP & Traditional irrigation systems & Irrigation systems \\
\hline & SMECAO & $\begin{array}{l}\text { Energy saving stoves, Tree nurses and } \\
\text { conservation of water sources }\end{array}$ & Stoves \& tree planting \\
\hline \multirow{4}{*}{ Same } & SAIPRO & $\begin{array}{l}\text { Irrigation, tree planting, income generation } \\
\text { activities and dry land agriculture }\end{array}$ & $\begin{array}{l}\text { Irrigation, tree planting and } \\
\text { income generation }\end{array}$ \\
\hline & FIDE & Biogas and alternation energy sources & Alternation energy \\
\hline & SMECAO & \multicolumn{2}{|c|}{ See Mwanga above } \\
\hline & FBOS & $\begin{array}{l}\text { Tree plants, irrigation, income generation } \\
\text { activities and alternative energy }\end{array}$ & Tree planting, stoves, irrigation \\
\hline \multirow{3}{*}{ Siha } & TATEDO & Alternative energy, efficient stoves, Tree planting & Stoves and tree planting \\
\hline & OHINYI & Micro financing & Micro-financing \\
\hline & IVAENYI & Credit facilities and biogas & Micro financing, biogas \\
\hline \multirow{2}{*}{ Hai } & TATEDO & \multicolumn{2}{|l|}{ See above } \\
\hline & TACRI & Improved coffee varieties, shade trees & Improved agriculture \\
\hline \multirow{6}{*}{ Moshi Rural } & FBOs & \multicolumn{2}{|l|}{ See above } \\
\hline & Shoot \& Roots & Tree planting & Tree planting \\
\hline & TATEDO & \multicolumn{2}{|l|}{ See above } \\
\hline & TACRI & \multicolumn{2}{|l|}{ See above } \\
\hline & FLORESTA & \multicolumn{2}{|c|}{ Conservation of water sources \& tree planting as well as promotion of indigenous crops? } \\
\hline & Pangani Water Basin & Management of water resources & Water resources \\
\hline \multirow{6}{*}{$\begin{array}{l}\text { Moshi } \\
\text { Municipal }\end{array}$} & MUWASA & Management of water resources & Water resources \\
\hline & Pangani Water Basin & \multicolumn{2}{|l|}{ See above } \\
\hline & FITI & Tree planting, training and beekeeping & Trainings, tree planting \\
\hline & Tanzania Forest Services & Tree planting, forest management & Tree planting \& forest management \\
\hline & Green Garden & Tree nursing and efficient stoves & Tree planting \\
\hline & KIWAMA & Tree nursing & Tree planting \\
\hline \multirow{6}{*}{ Rombo } & CARMATEC & Energy serving technologies, biogas & Alternative energy \\
\hline & TATEDO & \multicolumn{2}{|l|}{ See above } \\
\hline & ENVIRONCARE & Tree planting and energy saving stoves & Stoves, tree planting \\
\hline & TACRI & See above & \\
\hline & KEDA & Tree planting & Tree planting \\
\hline & Seliani Agric Research & Agroforesty research & Agroforesty promotion \\
\hline
\end{tabular}

- Take immediate measures to implement a capacity building program for mainstreaming SLM activities in the region based on the identified knowledge gaps.

- Decide on immediate measures to be taken to address the identified staffing problem at ward level in all the districts.

- Continue their efforts to develop memorandum of understanding with identified potential collaborators in the region for collaborative delivery of extension services.

\section{Acknowledgements}

The author wishes to acknowledge the financial support provided by the UNDP Tanzania Office through the Sustainable Land Management project in Kilimanjaro for conducting this study. The support provided by the regional and district levels teams of experts to the author during the assessment period is highly appreciated.

\section{References}

[1] Kessy, J.F., Oktingati, A. and Solberg, B. (1993) The Economics of Rehabilitating Denuded Areas in Tanzania: The 
Case of Legho Mulo Moshi. Faculty of Forestry Record No. 60, Sokoine University of Agriculture.

[2] Kessy, J.F. and Oktingati, A. (1994) An Analysis of Some Socio-Economic Factors Affecting Farmer's Involvement in Agroforestry Extension Projects in Tanzania. Annals of Forestry, 2, 26-32.

[3] Oktingàti, A. and Kessy, J.F. (1991) The Farming Systems on Mount Kilimanjaro. In: Newmark, W.D., Ed., Conservation of Mount Kilimanjaro, Chapter 8, IUCN, Gland.

[4] Flora, K., Mashindano, O., Rweyemam, D. and Charles, P. (2011) Poverty Escape Routes in Central Tanzania: Copping Strategies in Singida and Dodoma Regions. Volume III, The Economic and Social Research Foundation (ESRF), Dar es Salaam.

[5] Kessy, J.F. (1998) Conservation and Utilization of Natural Resources in the East Usambara Forest Reserves: Conventional Views and Local Perspectives. Tropical Forest Management Papers No. 18, Wageningen.

[6] UNDP (2007) Capacity Assessment Methodology. Users Guide, Capacity Development Group, Bureau for Development Policy, UNDP.

[7] Wignaraja, K. (2009) Capacity Development: A UNDP Primer. UNDP, USA.

[8] Miller, J.A. and Osinski, D.M. (2002) Training Needs Assessment. http://www.ispi.org/pdf/suggestedReading/Miller_Osinski.pdf

[9] Chris, B., Sparrow, P., Vernon, G. and Houldsworth, E. (2011) International Human Resources Management. 3rd Edition, Chartered Institute of Personnel and Development, London.

[10] Itika, J. (2011) Fundamentals of Human Resources Management: Emerging Experiences from Africa. African Public Administration and Management Series, Vol. 2, African Studies Centre, Leiden.

[11] Robert, L. and Hendon, J. (2012) Human Resources Management: Functions, Applications, Skill Development. Sage Publications, Thousand Oaks. 
Scientific Research Publishing (SCIRP) is one of the largest Open Access journal publishers. It is currently publishing more than 200 open access, online, peer-reviewed journals covering a wide range of academic disciplines. SCIRP serves the worldwide academic communities and contributes to the progress and application of science with its publication.

Other selected journals from SCIRP are listed as below. Submit your manuscript to us via either submit@scirp.org or Online Submission Portal.
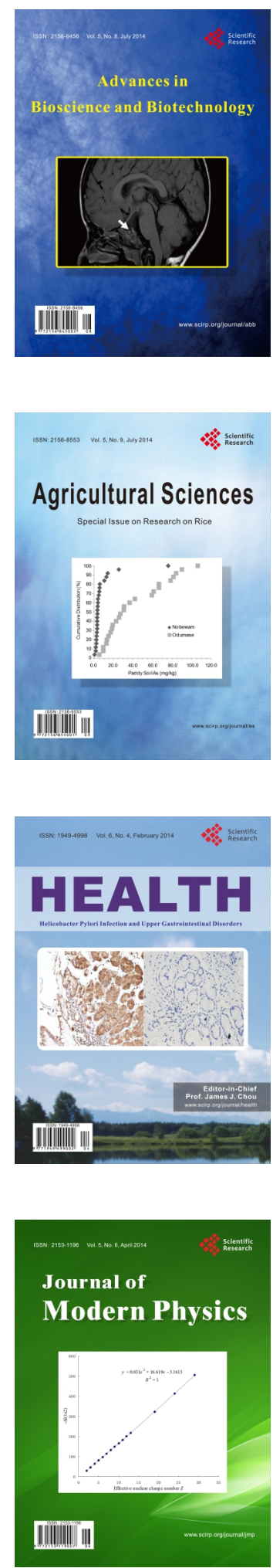
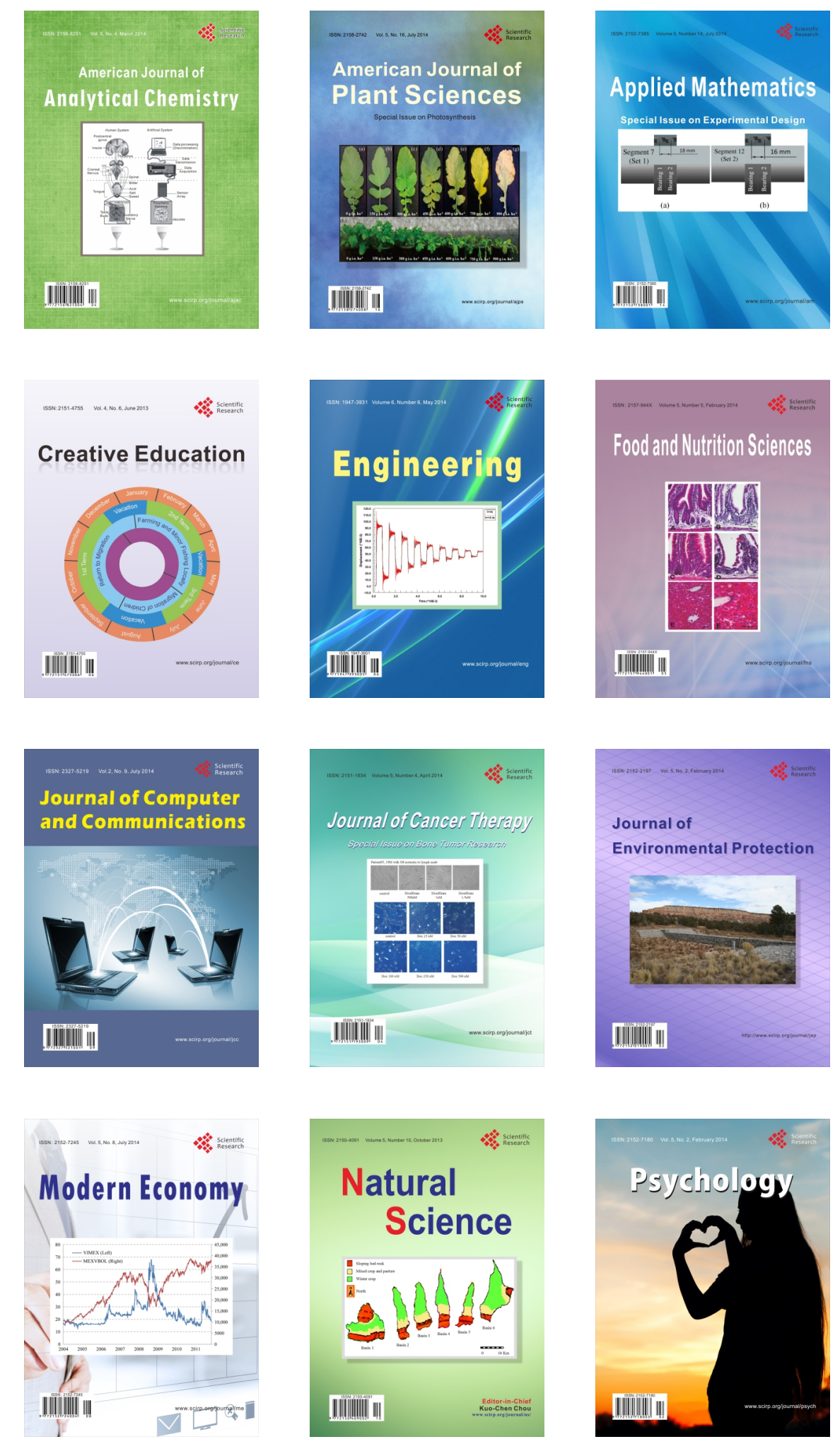